\title{
Diagnóstico molecular da tuberculose pulmonar
}

\author{
Molecular diagnosis of pulmonary tuberculosis
}

Nelma Cristina Sousa de Assis' ${ }^{1}$, Maria Luiza Lopes ${ }^{2}$, Ninarosa Calzavara Cardoso ${ }^{3}$, Maurimélia Mesquita da Costa ${ }^{4}$, Cintya de Oliveira Sousa ${ }^{4}$, Karla Valéria Batista Lima ${ }^{5}$

\begin{tabular}{|c|c|}
\hline & resumo \\
\hline M. tuberculosis & A reação em cadeia da polimerase (PCR) e suas variações, como a nested-PCR, têm sido destacadas como \\
\hline edrculose & técnicas moleculares promissoras para o diagnóstico rápido da tuberculose (TB). No presente e \\
\hline antigenc & avaliou-se a nested-PCR utilizando-se como marcadores moleculares a seqüência IS6110 e o antígeno \\
\hline antigen & ostras \\
\hline 110 & clínicas de pacientes com suspeita de TB. O diagnóstico de tuberculose pulmonar foi atribuído a 116 \\
\hline Nested-PCR & $\begin{array}{l}\text { pacientes e, desses, } 97 \text { foram multibacilares e } 111 \text { apresentaram cultura positiva para M. tuberculosis. } \\
\text { As reações de nested-PCR identificaram } 70 \% \text { (antígeno b) e } 94 \% \text { (IS6110) dos casos paucibacilares. Os }\end{array}$ \\
\hline $\mathrm{PC}$ & $\begin{array}{l}\text { valores de sensibilidade determinados para cultura, nested-PCR do IS6110 e antígeno b foram } 95 \% \text {, } \\
98 \% \text { e } 86 \% \text {, respectivamente. A especificidade foi de 100\%, } 15 \% \text { e } 45 \% \text { para cultura, nested-PCR do } \\
\text { IS } 6110 \text { e antígeno b, respectivamente. O diagnóstico molecular da tuberculose deve estar fundamentado } \\
\text { na análise conjunta de vários parâmetros, como baciloscopia, cultura, manifestações clínicas, prova } \\
\text { terapêutica e história prévia de tuberculose. }\end{array}$ \\
\hline
\end{tabular}

abstract

Chain reaction of polimerase $(P C R)$ and its variations such as the nested-PCR have been outstanding as promising molecular techniques for the fast diagnosis of the tuberculosis (TB). In the present study the nested-PCR was evaluated using as molecular markers the sequence IS6110 and the antigen $b$ applied to the diagnosis of TB. One hundred and thirty six clinical samples of patients with suspicion of TB were submitted to the baciloscopia, culture and nested-PCR. The diagnosis of pulmonary tuberculosis was attributed to 116 patients, of these, 97 were multi-bacilli and 111 presented positive culture for M. tuberculosis. The nested-PCR reactions identified 70\% (antigen b) and 94\% (IS6110) of the acid-fast smear negative cases of tuberculosis. The sensibility values determined for culture, and nested-PCR of IS6110 and antigen $b$ were $95 \%, 98 \%$ and $86 \%$, respectively. The specificity was 100\%, 15\% and $45 \%$ for culture, nested-PCR of IS6110 and antigen $b$, respectively. The molecular diagnosis of the tuberculosis should be based in the combined analysis of several parameters, as the baciloscopia, culture, clinical manifestations, therapeutic proves and previous history of tuberculosis.

key words

M. tuberculosis

Tuberculosis

antigen $b$

IS6110

Nested-PCR

$P C R$

1. Mestranda do Programa de Pós-Graduação em Saúde, Sociedade e Endemias na Amazônia da Universidade Federal do Pará (UFPA).

2. Pesquisadora responsável pelo Laboratório de Micobactérias da Seção de Bacteriologia e Micologia (Sebac) do Instituto Evandro Chagas (IEC), Secretaria de Vigilância em Saúde (SVS), Ministério da Saúde (MS).

3. Médica pneumologista da referência em pneumologia do Centro de Saúde Escola do Marco, Universidade Estadual do Pará (Uepa).

4. Pesquisadoras da Sebac/IEC/SVS/MS.

5. Pesquisadora responsável pelo Laboratório de Biologia Molecular da Sebac/IEC/SVS/MS.

Trabalho realizado no Laboratório de Biologia Molecular da Sebac/IEC/SVS/MS.

Apoio financeiro: Fundo Estadual de Ciência e Tecnologia da Secretaria Executiva de Ciência e Tecnologia do Pará, convênio entre Secretaria Executiva de Ciência, Tecnologia e Meio Ambiente

(Sectam), Fundo Tecnológico (Funtec), MS, Conselho Nacional de Desenvolvimento Cientifico e Tecnológico (CNPq) e IEC no 102/2004. 


\section{Introdução}

Avanços no campo da biologia molecular têm gerado novas técnicas para o diagnóstico de infecções por meio da detecção de seqüências nucleotídicas específicas dos microrganismos $^{(11)}$. A reação em cadeia mediada pela polimerase (PCR) tem se destacado como uma das mais promissoras técnicas moleculares para o diagnóstico rápido de doenças infecciosas $^{(4)}$. Embora a PCR simples seja bastante útil para detecção do M. tuberculosis, um procedimento que associa duas PCR (nested-PCR) concilia maiores sensibilidade e especificidade ${ }^{(16)}$. Miyazaki et al. ${ }^{(16)}$, ao analisarem a técnica de diagnóstico da tuberculose por nested-PCR, relataram um limite de detecção para a primeira PCR de $10^{2}$ UFC com aumento de mil vezes após a segunda reação e sensibilidade de até 0,1 UFC.

O custo da PCR na rotina é factível, considerando que o diagnóstico rápido em pacientes paucibacilares permite instituir o tratamento específico o mais precocemente possível, diminuindo assim as fontes bacilíferas e, com elas, a infecção pelo M. tuberculosis, portanto reduzindo a cadeia de transmissão. O desenvolvimento e a padronização, próprios para o teste, tornam seu custo mais acessível, tendo em vista que essa tecnologia deve ser reservada para centros de referência na investigação de casos que demandem diagnósticos rápidos ${ }^{(5)}$.

Vários elementos repetitivos de DNA que contribuem para a variação genética de cepas foram descobertos em $M$. tuberculosis. Um deles é a seqüência de inserção IS6110 (28), que é um elemento genético de 1.350 pares de bases que está exclusivamente presente nas espécies do complexo M. tuberculosis ${ }^{(12,29,30)}$ em diferentes números de cópias e integrado em vários sítios cromossômicos. Além da IS6110, outras seqüências alvo têm sido utilizadas no diagnóstico molecular da tuberculose, como genes que codificam proteínas de $32 \mathrm{kDa}, 38 \mathrm{kDa}, 65 \mathrm{kDa}$, a proteína MPB64 e os genes dnal e mtp $40^{(8,15,16,20,25,27)}$.

O presente trabalho avaliou a nested-PCR, utilizando como alvos moleculares a seqüência IS6110 ${ }^{(9,4)}$ e o gene que codifica uma proteína de $38 \mathrm{kDa}$ (antígeno b) (1, 16) $^{-1}$ aplicados ao diagnóstico da tuberculose.

\section{Material e método}

Foram analisadas 136 amostras de escarro de pacientes encaminhados do Centro de Saúde Escola do Marco (CSEM) ao Laboratório de Tuberculose do Instituto Evandro Chagas (PA) com suspeita clínica de tuberculose para a realização da baciloscopia, cultura e PCR. As amostras foram encaminhadas no período de outubro de 2002 a abril de 2004.

A baciloscopia foi realizada pelo método de Ziehl-Neelsen, enquanto a cultura foi feita em meio Löwnestein-Jensen após tratamento com laurilsulfato de sódio, segundo o Manual de Bacteriologia da Tuberculose $e^{(7)}$.

O DNA micobacteriano foi extraído diretamente do escarro após fluidificação com N-acetilcisteína a $20 \mathrm{mg} / \mathrm{ml}$ e tratado com proteinase $\mathrm{K}$ e fenol-clorofórmio. Cada $1 \mathrm{ml}$ do escarro foi tratado com $1 \mathrm{ml}$ de $\mathrm{N}$-acetilcisteína, homogeneizado, incubado a $37^{\circ} \mathrm{C}$ por 12 horas aproximadamente e centrifugado por 10 minutos a $5.000 \mathrm{rpm}$. Ao precipitado adicionaram-se $100 \mu \mathrm{l}$ de tampão de homogeneização (trisHCL 1 M, pH 8; $\mathrm{NaCl} 1 \mathrm{M}$; ácido etilenodiaminotetracético [EDTA] 0,5 M, pH 8; sacarose), $100 \mu \mathrm{l}$ de tampão de lise (tris-HCL 1 M, pH 9; EDTA 10 mM, pH 8; sucrose 20\%, dodecil sulfato de sódio [SDS] 10\%) e $5 \mu$ le proteinase $\mathrm{K}$ $(10 \mathrm{mg} / \mathrm{ml})$. Essa mistura foi incubada a $56^{\circ} \mathrm{C}$ por 12 horas. À temperatura ambiente, foram adicionados $200 \mu \mathrm{l}$ de fenol-clorofórmio-álcool isoamil (25:24:1), depois homogeneizados por 10 minutos e centrifugados a 13.000 rpm por 10 minutos. A extração foi repetida com $200 \mu$ de clorofórmio-álcool isoamil (24:1). O sobrenadante foi transferido para outro tubo e adicionaram-se $30 \mu \mathrm{l}$ de acetato de sódio (3 M, pH 4,8) e $150 \mu \mathrm{l}$ de isopropanol para precipitação do DNA. O DNA foi, então, lavado com $500 \mu$ l de etanol a 70\%, seco a $37^{\circ} \mathrm{C}$ e ressuspenso em tampão EDTA.

As reações de nested-PCR para cada seqüência alvo (IS6110 e antígeno b) foram realizadas para um volume de $50 \mu$ contendo $1 \mathrm{mM}$ a 2,5 mM de $\mathrm{MgCl}_{2}, 0,12 \mathrm{mM}$ de cada desoxinucleotídeo, 200 ng de cada iniciador, glicerol a 10\%, tampão da Taq 1X, 0,5 U da enzima Taq DNA polimerase (Invitrogen) e 20 a 100 ng do DNA alvo. As seqüências dos iniciadores para os respectivos DNA alvos e as condições da PCR estão descritas na Tabela 1.

Os produtos amplificados foram submetidos à eletroforese em gel de agarose a $1 \%$, corados com $1 \mu \mathrm{g} / \mathrm{ml}$ de brometo de etídio e visualizados em transiluminador de luz ultravioleta.

O critério para definição de caso de tuberculose foi a baciloscopia positiva ou o isolamento do espécime por cultivo, ou clínica de tuberculose com prova terapêutica positiva.

A análise dos resultados foi feita avaliando-se o índice de kappa (к) na verificação de concordância ${ }^{(24)}$ entre os casos de tuberculose e os métodos de diagnóstico. Essa análise foi realizada por meio do programa BioEstat 3.0(2).

A sensibilidade e a especificidade foram calculadas, segundo Fletcher et $a l_{.}{ }^{(10)}$, comparando os testes diagnós- 
Tabela 1 Seqüências dos iniciadores e condiçōes da PCR

\begin{tabular}{|c|c|c|c|}
\hline Alvos & Sequiência dos iniciadores & Produto amplificado & Ciclos \\
\hline \multirow[t]{2}{*}{ IS6110 e antígeno $\mathrm{b}^{1}$} & $\begin{array}{l}\text { Externos (Del Portillo et al., 1996) } \\
\text { 5'-CGGAGACGGTGCGTAAGTGG-3' } \\
\text { 5'-GATGGACCGCCAGGGCTTGC-3' }\end{array}$ & $984 \mathrm{pb}$ & $\begin{array}{l}94^{\circ} \mathrm{C}-1 \min \\
63^{\circ} \mathrm{C}-1 \min 40 \mathrm{x} \\
72^{\circ} \mathrm{C}-1 \min \end{array}$ \\
\hline & $\begin{array}{l}\text { Internos (Bollela et al., 1999) } \\
\text { 5'-CCTGCGAGCTAGGC GTC GG-3' } \\
\text { 5'-CTCGTCCAGCGCCGCTTCGG-3' }\end{array}$ & $123 \mathrm{pb}$ & $\begin{array}{l}94^{\circ} \mathrm{C}-1 \min \\
62^{\circ} \mathrm{C}-1 \min 40 \mathrm{x} \\
72^{\circ} \mathrm{C}-1 \min \end{array}$ \\
\hline \multirow[t]{2}{*}{ Antígeno $b^{1}$} & $\begin{array}{l}\text { Externos (Miyazaki et al., 1993) } \\
\text { 5'-ACCACCGAGCGGTTCGCCTGA-3' } \\
\text { 5'-GATCTGCGGGTCGTCCCAGGT-3' }\end{array}$ & $400 \mathrm{pb}$ & $\begin{array}{l}94^{\circ} \mathrm{C}-1 \min \\
63^{\circ} \mathrm{C}-1 \min 40 \mathrm{x} \\
72^{\circ} \mathrm{C}-1 \min \end{array}$ \\
\hline & $\begin{array}{l}\text { Internos (Miyazaki et al., 1993) } \\
\text { 5'-TGACGTTGGCGGAGACCG-3' } \\
\text { 5'-ATGGTGCCCTGGTACATG-3' }\end{array}$ & $340 \mathrm{pb}$ & $\begin{array}{l}94^{\circ} \mathrm{C}-1 \min \\
51^{\circ} \mathrm{C}-1 \min 40 \mathrm{x} \\
72^{\circ} \mathrm{C}-1 \min \end{array}$ \\
\hline
\end{tabular}

ticos (baciloscopia, cultura, nested-PCR para o antígeno b e nested-PCR para o IS6110) com os casos de tuberculose.

O projeto que deu origem a este trabalho foi submetido e aprovado pelo Comitê de Ética em Pesquisa do Instituto Evandro Chagas (Protocolo CEP/IEC - No 008/2004, aprovado em 22 de dezembro de 2004). Foram observados os cuidados necessários para preservar a liberdade de consentimento dos pacientes envolvidos.

\section{Resultados}

Entre os 136 casos investigados, 116 foram caracterizados como tuberculose pelos critérios adotados. A cultura foi positiva em 111 amostras, sendo 97 positivas e 14 negativas (Tabela 2). Em duas amostras com baciloscopia positiva, uma apresentou contaminação da cultura e outra não mostrou crescimento no cultivo. Esses dois casos foram considerados tuberculose, bem com outros três casos com resultados de cultura e baciloscopia negativos, apresentando dados clínico-radiológicos suspeitos, que apresentaram melhora clínica após tratamento.

A nested-PCR foi positiva em 111 amostras para o antígeno b e em 131 para a IS6110. As relações entre os resultados obtidos em cultura, baciloscopia e nested-PCR são mostradas nas Tabelas $\mathbf{2}$ e $\mathbf{3}$.

A nested-PCR para o IS6110 identificou $94 \%$ dos casos de tuberculose paucibacilar (Figura). Entre as análises, a nested-PCR para a IS6110 apresentou a maior sensibilidade e a menor especificidade (Tabela 4).

A análise de concordância entre os casos considerados tuberculose e os resultados obtidos pela cultura e pela nested-PCR, diferenciando os marcadores moleculares, são apresentados na Tabela 5.

\section{Tabela 2 Comparação entre os resultados de cultura, baciloscopia e nested-PCR para 0 antígeno b}

\begin{tabular}{lccccc}
\hline & \multicolumn{2}{c}{ Cultura positiva } & \multicolumn{2}{c}{ Cultura negativa } & \\
\cline { 2 - 5 } & $\begin{array}{c}\text { Baciloscopia } \\
\text { positiva }\end{array}$ & $\begin{array}{c}\text { Baciloscopia } \\
\text { negativa }\end{array}$ & $\begin{array}{c}\text { Baciloscopia } \\
\text { positiva }\end{array}$ & $\begin{array}{c}\text { Baciloscopia } \\
\text { negativa }\end{array}$ & Total \\
N-PCR para antígeno b positivo & 86 & 11 & $2^{*}$ & 12 & 111 \\
N-PCR para antígeno b negativo & 11 & 3 & 0 & 11 & 25 \\
Casos de tuberculose** & 97 & 14 & 2 & 3 & 116 \\
Total de casos investigados & 97 & 14 & 2 & 23 & 136 \\
\hline
\end{tabular}

*Em um caso houve contaminação da cultura e em outro, cultura negativa; **os casos de tuberculose foram definidos usando-se como critérios a baciloscopia positiva, ou isolamento do espécime por cultivo, ou clínica de tuberculose com prova terapêutica positiva. 


\section{Tabela 3 Comparação entre os resultados de cultura, baciloscopia e nested-PCR para IS6110}

\begin{tabular}{lccccc}
\hline & \multicolumn{2}{c}{ Cultura positiva } & \multicolumn{2}{c}{ Cultura negativa } \\
& $\begin{array}{c}\text { Baciloscopia } \\
\text { positiva }\end{array}$ & $\begin{array}{c}\text { Baciloscopia } \\
\text { negativa }\end{array}$ & $\begin{array}{c}\text { Baciloscopia } \\
\text { positiva }\end{array}$ & $\begin{array}{c}\text { Baciloscopia } \\
\text { negativa }\end{array}$ & Total \\
N-PCR para IS6110 positivo & 96 & 14 & $2 *$ & 19 & 131 \\
N-PCR para IS6110 negativo & 1 & 0 & 0 & 4 & 5 \\
Casos de tuberculose** & 97 & 14 & 2 & 3 & 116 \\
Total de casos investigados & 97 & 14 & 2 & 23 & 136 \\
\hline
\end{tabular}

*Em um caso houve contaminação da cultura e em outro, cultura negativa.

${ }^{*}$ Os casos de tuberculose foram definidos usando-se como critérios a baciloscopia positiva, ou isolamento do espécime por cultivo, ou clínica de tuberculose com prova terapêutica positiva.

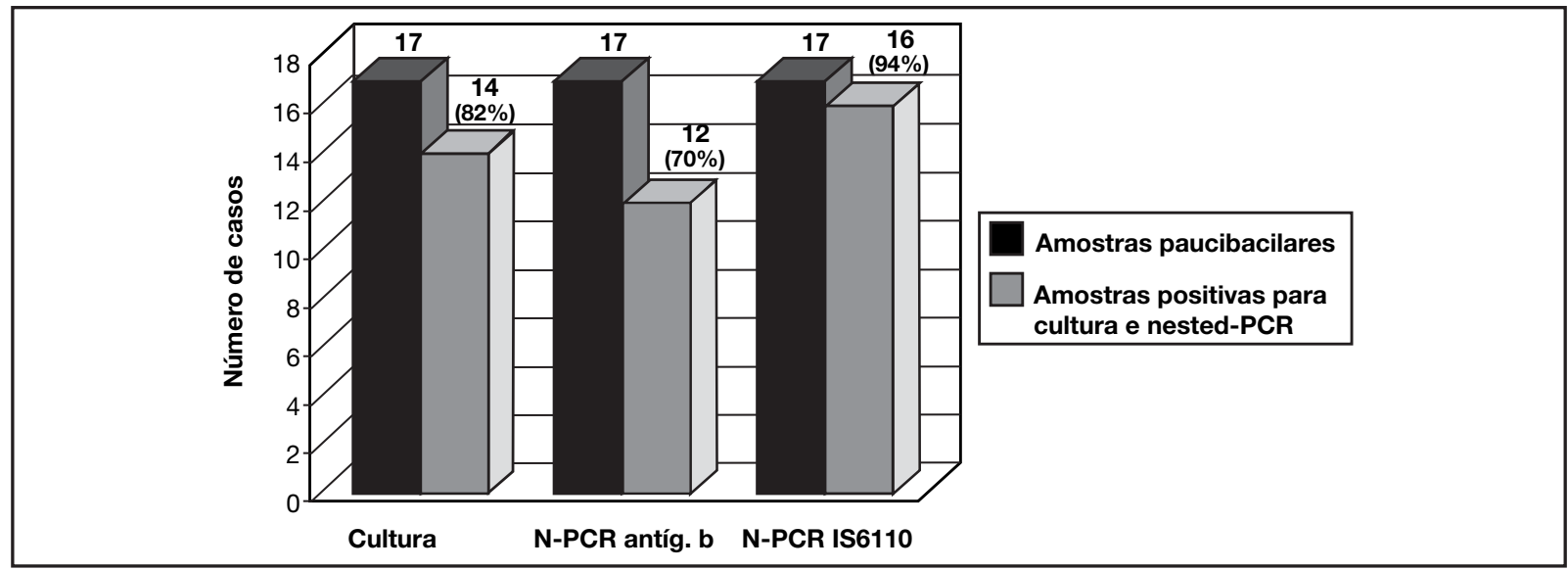

Figura - Percentuais de positividade dos métodos de diagnóstico (cultura e nested-PCR) nos casos de tuberculose paucibacilar

Tabela 4

\section{Valores de sensibilidade ( $\mathbf{S})$, especificidade (E), falso-positivo e falso-negativo para as 136}

Métodos diagnósticos

Cultura

N-PCR antígeno b

N-PCR IS6110

amostras de escarro analisadas pelos métodos molecular e convencional

Sensibilidade: proporção dos indivíduos com a doença que têm um teste positivo para ela, ou seja, capacidade de detectar o bacilo em amostras contaminadas; especificidade: proporção dos indivíduos sem a doença que têm um teste negativo para ela, ou seja, capacidade de não detectar o bacilo em amostras não contaminadas.

Tabela 5

Resultados de concordância dos testes diagnósticos em relação aos casos considerados tuberculose

\begin{tabular}{|c|c|c|c|c|c|c|c|}
\hline & & \multicolumn{2}{|c|}{ Cultura } & \multicolumn{2}{|c|}{ IS6110 (123 pb) } & \multicolumn{2}{|c|}{ Antígeno b (38 kDa) } \\
\hline & & Pos & Neg & Pos & Neg & Pos & Neg \\
\hline Casos de & Pos & 111 & 5 & 114 & 2 & 100 & 16 \\
\hline tuberculose & Neg & 0 & 20 & 17 & 3 & 11 & 9 \\
\hline \multicolumn{2}{|l|}{ Total } & \multicolumn{2}{|c|}{136} & \multicolumn{2}{|c|}{136} & \multicolumn{2}{|c|}{136} \\
\hline \multicolumn{2}{|c|}{ Concordância observada (\%) } & \multicolumn{2}{|c|}{96,3} & \multicolumn{2}{|c|}{86} & \multicolumn{2}{|c|}{80,1} \\
\hline \multicolumn{2}{|c|}{ Concordância esperada (\%) } & \multicolumn{2}{|c|}{72,3} & \multicolumn{2}{|c|}{82,7} & \multicolumn{2}{|c|}{72,3} \\
\hline \multicolumn{2}{|c|}{ Índice de kappa (к) } & \multicolumn{2}{|c|}{0,8672} & \multicolumn{2}{|c|}{0,1925} & \multicolumn{2}{|c|}{0,2828} \\
\hline \multicolumn{2}{|c|}{ Interpretação $(\kappa)$} & \multicolumn{2}{|c|}{ Forte } & \multicolumn{2}{|c|}{ Leve } & \multicolumn{2}{|c|}{ Leve } \\
\hline
\end{tabular}

Pos: positivo, Neg: negativo. 


\section{Discussão e conclusões}

A análise dos resultados obtidos identificou a nested-PCR para IS6110 como a técnica molecular de maior sensibilidade (98\%) quando em comparação com a PCR para o gene codificante do antígeno b (86\%). No Amazonas, Ogusku e Salem ${ }^{(19)}$ obtiveram positividade de $92 \%$ e $87 \%$ na PCR quando utilizaram como marcador molecular o IS6110 e o antígeno $b$, respectivamente, para o diagnóstico da tuberculose pulmonar. Segundo os autores, devido à seqüência IS6110 estar presente em múltiplas cópias no genoma do M. tuberculosis, há uma maior sensibilidade da PCR em comparação com amplificações de seqüências de cópias únicas (38kDa, 65kDa, MPB64), mesmo quando essas são submetidas a nested-PCR.

Querol et al. ${ }^{(23)}$ utilizaram PCR para amplificar um fragmento de 123 pb da seqüência de inserção IS6110 e obtiveram positividade em $97 \%$ dos 105 pacientes com diagnóstico clínico de tuberculose. Os autores relatam, ainda, que todos os casos de cultura positiva tiveram PCR positivo.

No presente estudo, 14 amostras de escarro com cultura positiva apresentaram resultado negativo na PCR para o antígeno b, e uma também apresentou resultado negativo para a IS6110. Esse fato pode ter sido causado pela presença de substâncias inibidoras da enzima DNA polimerase ou pelo exaustivo processo de extração. Observa-se que um dos pontos importantes para o uso da PCR no diagnóstico é a obtenção de DNA de qualidade a partir de amostras clínicas. A qualidade do escarro também pode influenciar diretamente na positividade da PCR. Quanto mais representativa do trato respiratório inferior for a amostra, melhor será o rendimento da detecção molecular ${ }^{(3)}$.

Suffys et al. ${ }^{(26)}$ avaliaram a PCR como ferramenta para o diagnóstico da tuberculose pulmonar por meio da amplificação de uma região de 178 pb da seqüência IS6110 do M. tuberculosis, no entanto relataram positividade em $44 \%$ das amostras de escarro com diagnóstico clínico e radiológico de tuberculose. A baixa sensibilidade foi justificada pela introdução de substâncias inibidoras durante o procedimento de extração com sílica-guanidinatiocianato. Bollela et al. ${ }^{(4)}$ defendem a lavagem exaustiva do DNA obtido de escarro para eliminação de substâncias inibidoras da enzima Taq DNA polimerase.

O procedimento de extração de DNA micobacteriano utilizado neste trabalho envolveu várias etapas para purificação do DNA, entretanto diversas foram as possibilidades de perda do DNA, desde a escolha da porção mais adequada do escarro a ser trabalhada até a perda durante transferên- cia da fração aquosa após partição em líquidos imiscíveis, centrifugação, lavagens e secagem prolongada.

Os dados apresentados neste trabalho revelam um elevado número de resultados falso-positivos usando o IS6110 (16 casos) ou o antígeno b (9 casos) como marcadores moleculares. Tais resultados podem ser atribuídos a contaminação da reação de amplificação por DNA (amplicons), presença de organismos não-viáveis em pacientes tratados ou pacientes com recidiva de tuberculose. O alvo para a PCR não é um microrganismo vivo como nas técnicas de cultivo de células, mas uma molécula de DNA que pode estar presente em uma amostra sem apresentar significado clínico. Pacientes com passado de tuberculose podem manter DNA do microrganismo por algum tempo ${ }^{(6)}$. Segundo Morán et al. (2000), resultados positivos na PCR podem refletir uma infecção ativa por M. tuberculosis ou passado de tuberculose ${ }^{(17)}$.

Em seis casos, negativos na baciloscopia e cultura, a nested-PCR permitiu constatar situação de passado de tuberculose (três casos positivos para a seqüência IS6110, dois casos positivos para o antígeno b e um caso positivo para os dois alvos moleculares). Esses pacientes foram acompanhados por até três anos e em nenhum deles foi diagnosticada tuberculose nos anos seguintes.

A introdução de ácidos nucléicos contaminantes na mistura da reação pode ocorrer por contaminação cruzada em uma amostra contendo um grande número de moléculas-alvo, por contaminação de reagentes com DNA derivado de amostras previamente analisadas e por acúmulo de produtos de PCR (amplicons) no laboratório, devido à repetida amplificação do mesmo alvo. Cada recipiente de PCR, após amplificação, pode conter aproximadamente $10^{12}$ cópias de um amplicon; assim, mesmo um diminuto aerossol pode conter um número significativo de contaminantes $(18,21,22)$.

Segundo Kox et al.(13), o risco da contaminação por amplicons pode ser removido pelo uso da uracil-N-glycosylase (UNG) e da incorporação da desoxiuridina trifosfato (dUTP) no lugar da desoxitimidina trifosfato (dTTP). A UNG atua na degradação dos amplicons contaminantes. Desse modo, espera-se reduzir as reações falso-positivas, com conseqüente aumento da especificidade da PCR para amostras clínicas. Para Noordhoek et al. ${ }^{(18)}$, o uso da dUTP-UNG será efetivo em evitar a contaminação das amostras com amplicons apenas se nenhuma contaminação prévia tiver ocorrido. Apesar das precauções especiais tomadas para evitar contaminação de soluções no desenvolvimento dos ensaios deste trabalho, situações não identificadas podem ter interferido na baixa especificidade da nested-PCR aplicada neste estudo. 
A ocorrência de resultados falso-positivos pode ser evitada quando algumas medidas de prevenção são seguidas, como: a) definir ambientes específicos para extração, preparo das reações de amplificação e eletroforese; b) autoclavar a água e soluções usadas na PCR; c) aliquotar e estocar os reagentes usados em uma área livre de produtos de PCR; d) usar luvas limpas durante a realização dos procedimentos; e) utilizar ponteiras com barreira ao manipular produtos de PCR; f) adicionar a amostra de DNA na PCR em ambiente distante do local de preparação da reação; $g$ ) usar controles negativos que sejam manipulados desde a extração do DNA; h) usar controles negativos a cada cinco ou 10 amostras trabalhadas ${ }^{(6,14)}$. Todos esses cuidados foram observados pela nossa equipe.

O uso da nested-PCR para o IS6110 permitiu identificar mais de $90 \%$ dos casos de tuberculose paucibacilar. A disponibilidade de uma ferramenta como a PCR é de grande utilidade para auxiliar em situações paucibacilares que exigem diagnóstico rápido, e dessa forma, possa contribuir para a instituição da terapêutica. No entanto, antes que tais exames se incorporem à rotina diagnóstica, devem-se realizar estudos comparativos e controlados para otimização da técnica, sem deixar de considerar a freqüência dos marcadores moleculares escolhidos.

Conclui-se que a nested-PCR pode ser utilizada como ferramenta auxiliar no diagnóstico da tuberculose, porém associada a outros métodos e sem deixar de considerar o histórico de tuberculose do paciente. Portanto, o diagnóstico com tuberculose deve estar fundamentado na análise conjunta de vários parâmetros, como baciloscopia, cultura, manifestações clínicas e a prova terapêutica, assim como a PCR, que é mais uma metodologia à disposição do diagnóstico rápido, desde que utilizada com rigoroso controle de qualidade.

\section{Referências}

I. ANDERSEN, B.; HANSEN, E. B. Structure and mapping of antigenic domains of protein antigen b, a 38.000 molecular weight protein of Mycobacterium tuberculosis. Infec Immu, v. 57, n. 8, p. 248I-8, 1989

2. AYRES, M. et al. BioEstat 3.0. Aplicações estatísticas nas áreas das ciências biológicas e médicas. Brasilia, CNPq, 2003.

3. BAZZO, M. L. et al. Relação entre a qualidade de amostras de escarro e o diagnóstico de micobactérias por PCR. In: Resumos do XXXVIII Congresso Brasileiro de Patologia Clínica e Medicina Laboratorial, 2004, Florianópolis. Disponível em: $<$ http://www.sbpc.org.br>. Acesso em: 30 nov. 2004.

4. BOLLELA, V. R.; SATO, D. N.; FONSECA, B. A. L. Problemas na padronização da reação em cadeia da polimerase para diagnóstico da tuberculose pulmonar. Rev Saúde Publ, v. 33 , n. 3, p. 281-6, 1999.

5. BRASIL. Diagnóstico da tuberculose. In: II Consenso Brasileiro de Tuberculose. Diretrizes Brasileiras para Tuberculose 2004.J Bras Pneumo, v. 30, n. I, p. 6-23, 2004.

6. BURKARDT, H. J. Standardization and quality control of PCR analyses. Clin Chem Lab Med, v. 38, n. 2, p. 87-9I, 2000.

7. CENTRO DE REFERÊNCIA PROFESSOR HÉLIO FRAGA. Fundação Nacional de Saúde. Manual de Bacteriologia da Tuberculose. 2. ed. Ministério da Saúde, Rio de Janeiro, 1994.

8. BRISSON-NOËL, A. et al. Rapid diagnosis of tuberculosis by amplification of mycobacterial DNA in clinical samples. Lancet, v. 4, p. 1069-7I, 1989.

9. DEL PORTILLO, P. et al. Multiprimer PCR system for differential identification of mycobacteria in clinical samples. J Clin Microbiol, v. 34, p. 324-8, 1996.
I 0. FLETCHER, R. H.; FLETCHER, S.W.;WAGNER, E. H. Diagnóstico. In: Epidemiologia clínica: elementos essenciais. Artmed: Porto Alegre, 1996.

I I. GARCÍA, M. Hibridación de ácidos nucleicos: fundamentos e aplicaciones. Bol Sanit Panam, v. 109, n. 3, 1990.

12. HERMANS, P.W. M. Insertion element IS986 from Mycobacterium tuberculosis: a useful tool for diagnosis and epidemiology of tuberculosis.J Clin Microbiol, v. 28, p. 205 I-8, 1990.

13. KOX, L. F. F. et al. A more realiable PCR for detection of Mycobacterium tuberculosis in clinical samples.J Clin Microbiol, v. 32, n. 3, p. 672-8, 1994.

14. KWOK, S.; HIGUCHI, R.Avoiding false positives with PCR. Nature, V. 339, p. 237-8, 1989.

15. MARTINS, L. C. et al. Nested-PCR using MPB64 fragment improves the diagnosis of pleural and meningeal tuberculosis. Rev Soc Bras Med Trop, v. 33, p. 253-7, 2000.

16. MIYAZAKI, Y. et al. Nested polymerase chain reaction for detection of Mycobcterium tuberculosis in clinical samples. Clin Microbiol, v. 31 , n. 8, p. 2228-32, 1993.

17. MORÁN, M. M. et al. Detección de Mycobacterium tuberculosis mediante la reacción en cadena de la polimerasa en una población seleccionada del noroccidente de México. Rev Panam Salud Pub, v. 7, p. 389-94, 2000.

18. NOORDHOEK, G.T. et al. Sensitivity and specificity of PCR for detection of Mycobacterium tuberculosis: a blind comparison study among seven laboratories. J Clin Microbiol, v. 32, n. 2, p. 277-84, 1994.

19. OGUSKU, M. M.; SALEM, J. I. Análise de diferentes primers utilizados na PCR visando ao diagnóstico da tuberculose 
no estado do Amazonas. | Bras Pneumol, v. 30, n. 4, p. 343-9, 2004.

20. PARRA, C. A. et al. Isolation, characterization, and molecular cloning of a specific Mycobacterium tuberculosis antigen gene, identification of a species-specific sequence. Infect Immun, v. 59, p. 34||-7, | 99 |.

21.PERSING, G.H. Polymerase chain reaction: trenches and benchs. J Clin Microbiol, v. 29, n. 7, p. 1281-5, 1991.

22. PERSING, D. H.; CIMINO, G.D.Amplification product inactivation methods. In: PERSING, D. H. et al. (eds.). Diagnostic molecular microbiology: principles and applications. Americ Soc Microbiol, p. 105-21. 1993.

23. QUEROL, J. M. et al. The utility of polymerase chain reaction (PCR) in the diagnosis of pulmonary tuberculosis. Clin Investig, v. 107, p. I631-5, 1995.

24. ROSSI, R. M. Bioestatística aplicada à residência médica. Fundação Universidade Estadual de Maringá. Centro de Ciências Biológica. Departamento de estatística. Disponível em: <http://www.des.uem.br/robson/cursos/bioaplic.htm>. Acesso em: 30 mar. 2005.

25. SOINI, H. et al. Detection and identification of mycobacteria by amplification of a segment of the gene coding for the
32 kilodalton protein. J Clin Microbiol, v. 30, n. 8, p. 2025-8, 1992.

26. SUFFYS, P. et al. Inhibition of the polymerase chain reaction by sputum samples from tuberculosis patients after processing using a silica- guanidiniumthiocyanate DNA isolation procedure. Memor Inst Oswaldo Cruz, v. 96, n. 8, p. 11 37-9, 2001.

27.TAKEWAKI, S. et al. Genus-specific polymerase chain reaction for the mycobacterial dnal gene and species specific oligonucleotide probes.J Clin Microbiol, v. 43, n. 2, p. 446-50, 1993.

28. THIERRY, D. IS6 / I0, an IS-like element of Mycobacterium tuberculosis complex. Nucleic Acid Res, v. 18, p. 188, 1999.

29.VAN SOOLINGEN, D. et al. Occurrence and stability of insertion sequences in Mycobacterium tuberculosis complex strains: evaluation of an insertion sequence-dependent DNA polymorphism as a tool in the epidemiology of tuberculosis. J Clin Microbiol, v. 31, p. 1987-95, 1991.

30. ZAINUDDIN, Z. F;; DALE, J.W. Polymorphic repetitive DNA sequences in Mycobacterium tuberculosis detected with a gene probe from a Mycobacterium fortuitum plasmid. J Gen Microbiol, v. I35, p. 2347-55, 1989. 